\title{
Direito à cidade contra o desenvolvimento
}

Right to the city against development

\section{Luana Xavier Pinto Coelho ${ }^{1}$}

1Universidade de Coimbra, Coimbra, Portugal. E-mail: Ixpcoelho@gmail.com. ORCID: https://orcid.org/0000-0002-0600-1667.

\section{Isabella Madruga da Cunha²}

'Universidade Federal do Paraná, Curitiba, Paraná, Brasil. E-mail: isabellamcunha@gmail.com. ORCID: https://orcid.org/0000-0002-3891-5551.

Artigo recebido em 3/02/2020 e aceito em 12/02/2020

\section{$(\mathrm{cc}))_{\mathrm{BY}}$}

This work is licensed under a Creative Commons Attribution 4.0 International License. 


\section{Resumo}

O artigo explora as formas pelas quais o direito à cidade e desenvolvimento são categorias opostas, em permanente tensão e disputa. Ao pensar o urbano recentralizando sujeitos e trajetórias historicamente desumanizadas, a partir das contribuições da crítica decolonial e antirracista, propomos que a vinculação política e jurídica da noção de direito à cidade à de desenvolvimento urbano captura e neutraliza as potencialidades da proposta lefebvriana.

Palavras-chave: Direito à cidade; Desenvolvimento urbano; Racismo.

\section{Abstract}

The article explores how the right to the city and development are opposite categories, in permanent tension and dispute. Engaging with decolonial theory and antiracist critique, we propose to think the urban re-centralizing historically dehumanized subjects and trajectories. The analysis suggests that political and legal connection of the right to the city conception to the urban development one captures and neutralizes the potentialities of the Lefebvrian proposition.

Keywords: Right to the city; Urban development; Racism. 


\section{Introdução}

Henri Lefebvre inicia O Direito à Cidade (2001 [1968]) com uma advertência, a qual nos serviu de provocação para propor a reflexão que segue e que gostaríamos de pôr como ponto de partida. O autor avisa que o livro que apresenta deseja romper com os sistemas, que ele entende como tendentes a aprisionar a reflexão fechando horizontes possíveis. Seu manifesto é contra uma reflexão baseada num formalismo, advogando pela abertura do pensamento e da ação em direção de "possibilidades que mostrem novos horizontes e caminhos" (Lefebvre, 2001:9). A proposta é de um pensamento criativo e inconformado, que desconfia das categorias dadas e estruturas aprisionantes; disposto a enfrentar os desafios de ir até a raiz dos problemas para produzir uma crítica radical com os pés no chão. É isto que anima este texto e as reflexões aqui compartilhadas.

Apontamos de início um desafio, a crítica decolonial denuncia as formas pelas quais categorias eurocêntricas foram homogeneizadas para serem impostas a todo o mundo, invisibilizando diversas outras formas de conhecimento, interpretação e compreensão da realidade (Quijano 2000; Walsh 2016; Espinosa-Miñoso 2014). Uma das mais bem elaboradas destas categorias é a de progresso, absorvida e substituída pela noção de desenvolvimento. Assumimos, assim, a provocação de pensar o Brasil, para o Brasil (com similitudes em nosso continente), refletindo sobre o urbano ${ }^{1}$ a partir da recentralização de sujeitos e trajetórias historicamente desumanizadas. Para tanto utilizamos duas chaves teóricas principais, a crítica decolonial e a crítica antirracista. A proposta decolonial elaborada a partir do conceito de colonialidade do poder (Quijano, 2014) considera a hierarquização racial entre as populações do mundo como eixo central da estruturação do poder capitalista, a partir da expansão da Europa com a colonização. Por outro lado, a crítica antirracista, a partir da reflexão sobre o racismo como desumanização (Fanon, 2008), irá contribuir para o entendimento da consolidação do capitalismo a partir da divisão racial do trabalho (Moura, 2019), conformar as espacialidades segregadas e naturalizar as linhas divisórias entre o normal e anormal/ humano e não humano a partir da hierarquização racial.

\footnotetext{
${ }^{1}$ Fenômeno urbano não se confunde com cidade na acepção lefebvriana, pois o urbano seria pós-industrial, um fenômeno que provoca a implosão-explosão da cidade, mas que inacabado apresenta-se como horizonte complexo (Lefebvre, 2008).
} 
Através de uma metodologia interdisciplinar e o método da revisão bibliográfica, este artigo objetiva opor as noções de direito à cidade e desenvolvimento urbano. Nossa hipótese é de que a vinculação política e jurídica da noção de direito à cidade à ideia de desenvolvimento urbano captura e neutraliza as potencialidades do que propôs Henri Lefebvre (2001), esvaziando o conceito. Nosso percurso passará, então, por uma apresentação da crítica ao desenvolvimento, historicizando e apresentando uma perspectiva que relaciona esse conceito à manutenção e aprofundamento de uma divisão internacional (racial) do trabalho baseada na acumulação por espoliação (Harvey, 2006; Quijano, 2014; Moura, 2019) que opera através da destruição de territórios e objetificação de corpos. Espoliação que só é possível através da naturalização de processos de desumanização de grupos humanos pelo racismo, através da chave-dual civilização e mundo selvagem (Maldonado-Torres, 2016; Grosfoguel, 2016; Goldberg, 2002; Wynter, 2003; Gonzalez, 1988; Nascimento et al. 2016; Quijano, 2000). Fala-se em território a partir de um entendimento das territorialidades e das produções de sentido desde múltiplas relações sócio-espaciais, como define Porto-Gonçalves (2006), território como terra mais cultura informado pelas relações de poder. Com isso queremos evidenciar que não se trata de uma violência puramente material ou econômica, mas também simbólica e cultural. No sentido de que a colonialidade do poder implica também na colonialidade do saber, do ser e da natureza (Walsh, 2014).

Trataremos, ainda, do entrelaçamento entre desenvolvimento e a questão ambiental, com a imposição do paradigma extrativista neodesenvolvimentista. Este modelo está baseado numa relação ambígua com o urbano, constituindo o ornitorrinco de que fala Francisco de Oliveira (2013): altamente urbanizado e forte agrobusiness. Ou seja, economias dependentes da extração e exportação de commodities - a natureza traduzida em mercadoria e ativo rentável. Embora atue simbolicamente no sentido de isolar e criar distância entre o urbano e o rural, que na prática estão inter-relacionados, opera na destruição de ambas relações territoriais pela voracidade da mercantilização com o objetivo de esvaziar o valor de uso e evidenciar o de troca. Para estabelecer estas relações buscaremos evidenciar o papel da categoria de raça e do racismo ${ }^{2}$ na

\footnotetext{
${ }^{2}$ Apesar da construção dos marcadores raciais serem dependentes do contexto da história colonial de determinado lugar, ela ainda determina a hierarquia social do superior/inferior (Grosfoguel 2016). Assim, compreendendo o racismo como um processo de desumanização que articula diversos níveis discursivos/
} 
engenharia do capitalismo, que para além de um modo de produção é um modelo civilizacional, enfocando a espacialização destas categorias na produção da cidade particularmente no Brasil. Sob esta perspectiva, a relação com a ordem urbanística ou o direito oficial apresenta-se historicamente como uma relação muito mais baseada na repressão do que na produção criativa de soluções que contemplem as territorialidades em conflito.

Retornando ao ponto de partida, a idéia de Lefebvre (2001) de direito à cidade nos serve como chave de análise porque ela propõe uma compreensão radical da democracia, pois envolve uma profunda produção democrática do espaço e, nesse sentido, contesta o sentido único "civilizatório" e colonial do planejamento urbano moderno e sua lógica científica (a verdade única) para planejar, destruir, construir, conformar, homogeneizar os vários modos de vida. Sem reivindicar um conceito puro ou primordial de direito à cidade, restringido ao que teorizou o filósofo, a proposta é convidar uma abordagem do direito à cidade que se desvencilhe da gramática desenvolvimentista. Trata-se, ao contrário, de ousar abrir brechas dentro de uma teoria do direito urbanístico que devido à herança colonial, vinculou a noção de direito à cidade ao progresso. No contexto de onde falamos, onde territórios e pessoas, divididos por uma linha de cor, são tratados pela política colonial-racista como matáveis e expropriáveis, pensar em democracia na produção do espaço não deixa de ser utópico, mas uma utopia necessária que leve ao movimento. Neste sentido, um direito à cidade da multiplicidade (Santos, 1995), decolonial e antirracista, só pode ser contra o desenvolvimento.

\section{A crítica ao desenvolvimento: extrativismo e colonialidade}

O conceito de desenvolvimento é mais um dentre o rol de noções importadas das ciências naturais, duras e/ou exatas, para as ciências sociais, humanas e/ou políticas. A primeira vez que desenvolvimento apareceu no sentido que referimos aqui foi em 20 de janeiro de 1949, no discurso de posse do presidente estadunidense Harry Truman. Nesse sentido, diz-se que a partir de então desenvolvido ou subdesenvolvido passou a

práticas, isto é, inclui os controles sobre os significados ontológicos e epistêmicos que davam (dão) contorno ao conceito de "civilização" em antagonismo ao ser/saber dos povos racializados no continente. 
referir o estado das economias e sociedades (Lang, 2016), tornando-se uma classificação designadora da situação dos Estados-nações do mundo. Como toda classificação necessita de indexadores, foram então criados indicadores universais como o PIB (Produto Interno Produto) e renda per capita para medir o nível de vida dos países de modo que, "começaram a ser comparadas sob um mesmo patamar as múltiplas formas diferentes de organizar a vida, os intercâmbios, a produção e a reprodução que existem no planeta" (Lang, 2016:30).

Inicialmente é possível encontrar dois problemas, que se desdobram em outros tantos, desta classificação universal. O primeiro é posto pela questão: o que fica de fora destes indicadores? Em um resumo grosseiro é possível responder: tudo o que está fora do sistema de trocas capitalista - que inclui as pessoas por meio da renda e do consumo - e da gestão estatal. O segundo está implícito e advém da hierarquia estabelecida entre os países desenvolvidos e os 'outros' - que não são radicalmente outros, mas cuja categorização toma-os vinculativamente aos desenvolvidos tornados padrão, ao serem definidos como (sub) menos ou em vias de desenvolvimento. Ou seja, estabeleceu-se um destino comum para todos: o desenvolvimento - o que não se conta é que o de uns é à custa de outros.

Para se analisar estas questões e alguns de seus desdobramentos, primeiro retomaremos o contexto em que surge a proposta do desenvolvimento, para depois abordar sua primeira oposição crítica, que identificamos como a repercussão política da pauta ambiental nos anos 1970. Em seguida, buscaremos demonstrar como a proposta do desenvolvimento não se refere apenas a um modelo econômico ultrapassado baseado em forte intervenção estatal, mas que ela se vinculou/vincula a diferentes modelos político-econômicos. Enfim, argumentaremos como a geografia da produção e da reprodução capitalista está baseada em uma divisão internacional (racial) do trabalho que designa papéis às nações e funda seu poder numa promessa que não pode cumprir: a do desenvolvimento. Esta promessa está vinculada ao horizonte do urbano, mas significa um único modelo de cidade. Este modelo é o que está associado ao desenvolvimento urbano.

No contexto do pós crise de 1929 e segunda guerra, surgiram teorias econômicas que em contraponto ao liberalismo clássico, defendiam a intervenção estatal como meio importante de prever e solucionar crises econômicas. As teorias econômicas de Kalecki, Keynes e Kaldor são os antecedentes teóricos da economia do 
desenvolvimento. O cerne da proposta da economia do desenvolvimento pode ser resumido na crença de que o crescimento econômico por si só poderia resolver a pobreza e a injustiça social, através de investimentos estatais. Eduardo Gudynas (2011) afirma que esta corrente teórica criou um entrelaçamento entre a noção de desenvolvimento, crescimento econômico e bem-estar humano.

Esta vinculação teórica entre crescimento econômico e justiça social fez com que o desenvolvimentismo rapidamente ganhasse adeptos das mais diversas posições, de países do norte e do sul global, de partidos de direita e de esquerda (Lang, 2016). De modo que, ao fim do século XX, consolidou-se um conceito de desenvolvimento como "processo de evolução linear, essencialmente econômico, mediado pela apropriação livre de recursos naturais, guiado por diferentes versões de eficiência e rentabilidade econômica, e orientado a emular o estilo de vida ocidental" (Gudynas, 2011: 23).

O cerne da nossa crítica ao desenvolvimentismo está nessa lógica de emulação do estilo de vida ocidental, que percebemos como o motor e mesmo a justificativa que embasa as ações que visam apropriar-se livremente de todos os espaços ditos livres, que na verdade são ocupados por outros modos de vida e relação com a natureza. Aí que reside a colonialidade do desenvolvimento. A colonialidade é definida por Aníbal Quijano (2014) como um dos elementos constitutivos e específicos do padrão de poder capitalista. Funda-se na imposição de uma classificação racial da população do mundo como pedra angular desse padrão de poder, operando em cada um dos planos, âmbitos e dimensões, materiais e subjetivas da vida e existência cotidiana em sociedade.

Nesse sentido, cabe retomar Lefebvre para quem, de acordo com seu leitor Edward Soja, a urbanização é uma metáfora da espacialização do capitalismo, de seus efeitos homogeneizantes, por meio de sua produção e reprodução baseada em um desenvolvimento geograficamente desigual (Soja, 1993). A ideia de desenvolvimento geograficamente desigual, desde nossa perspectiva foi melhor explorada pelas teorias da dependência (Marini, 2015) e do sistema-mundo moderno colonial (Wallerstein, 2007), demonstrando que o avanço do sistema capitalista por meio dos processos de colonização e globalização necessita da dualidade centro-periferia/norte-sul global. O que significa dizer que, ao mesmo tempo em que na busca de novos mercados e matérias-primas o capitalismo se expande provocando uma homogeneização, ele também acentua as diferenças. Essa perspectiva permite estabelecer uma crítica radical à economia do desenvolvimento, pois demonstra como a promessa do 
desenvolvimento, da igualação dos modos de vida e consumo entre os países e as gentes do norte e do sul global, é impossível dada sua premissa principal: o sistema capitalista ${ }^{3}$.

Uma nova dobra no conceito de desenvolvimento é proposta quando o fator ambiental se torna uma questão relevante na ordem político-jurídica internacional. Isto se dá a partir da introdução da ideia de crise ambiental no final dos anos 1960, por meio da publicação de estudos científicos ${ }^{4}$ que projetavam o colapso mundial tendo como tese central os limites físicos do planeta ao crescimento econômico e como proposta de ação o crescimento zero - econômico e populacional. A tese do crescimento zero colidia diretamente com a proposta de desenvolvimento para todas as nações do mundo, cujo conteúdo prático era o crescimento econômico ${ }^{5}$. Ao atacar um dos pilares da economia do desenvolvimento convencional a proposta foi rechaçada desde perspectivas à esquerda e à direita (Gudynas, 2011). É no contexto da emergência do projeto neoliberal, entre as décadas de 1980-90, que se constitui um cenário mais favorável ao relançamento da pauta ambiental. Deve-se isso especialmente à elaboração das noções de desenvolvimentos alternativos em que se destaca a proposta do desenvolvimento sustentável. O conceito mais reproduzido e citado de desenvolvimento sustentável é o divulgado em 1987 pelo Informe Brundtland, Nosso futuro comum, aprovado na Assembleia Geral da ONU. Aí desaparece a oposição entre conservação da natureza e desenvolvimento na gramática capitalista. A erradicação das contradições se faz pela

\footnotetext{
3 No debate feito por David Harvey sobre o desenvolvimento geográfico desigual, um dos elementos presentes na estruturação de suas condicionantes é a escala, ou seja, são os conflitos nessas diversas escalas geográficas que promovem o desenvolvimento geográfico desigual. (Santiago \& Carvalho, 2008). Apesar das críticas contemporâneas a este autor direcionarem sobretudo ao limite da categoria classe para compreender as desigualdades, a percepção de que os fenômenos estão interligados nas diversas escalas nos ajuda a refletir sobre o urbano em relação com o regional, nacional e o internacional. Particularmente no caso do Direito, por sua tendência a ser desespacializado, pensar nas escalas geográficas é territorializálo, sem que isso importe em redução do campo de análise.

${ }^{4}$ Pierri (2005) fornece um quadro elucidativo dos principais informes científicos que apresentavam o alarme inicial sobre os limites do meio ambiente. Destacamos "Silent Spring" (Primavera Silenciosa) 1962 de Rachel Carson, que denunciava o efeito dos agrotóxicos sobre a extinção de espécies de aves nos Estados Unidos; "The populationbomb" (A bomba populacional) 1968 de Paul Ehrlich, obra fundamental da corrente neomalthusiana; "O primeiro informe do Clube de Roma" de 1972 elaborado pelo prestigiado Instituto Tecnológico do Massachussets (MIT) sob coordenação de Meadows e nominado "The LimitstoGrowth" (Os limites para o crescimento) onde a proposta de crescimento zero foi sustentada e é considerado o documento mais contundente em estabelecer o consenso sobre a crise ambiental contemporânea.

${ }^{5}$ Não se tratava, porém, de uma tese periférica, mas de projeções propagadas pelo centro político do cenário da política internacional - representado pelos notáveis do Clube de Roma. O Clube de Roma foi fundado em 1966 pelo empresário italiano AurelioPeccei (fundador da Fiat) e por um cientista de prestígio, com o objetivo de se tornar um espaço de debates entre pessoas de destaque e poder nos campos empresarial, financeiro, econômico e científico. Fonte: www.wikipedia.com/www.clubofrome.org.
} 
afirmação que o desenvolvimento implica em crescimento econômico e que, para se atingir o desenvolvimento, a conservação dos recursos naturais é uma condição necessária. Este giro conciliador desenvolvimentista fez incluir um certo ambientalismo na matriz capitalista, aquele baseado em uma razão utilitária que compõe um conjunto de propostas de "modernização ecológica" cuja estratégia baseia-se em "afirmação do mercado, do progresso técnico e do consenso político" (Acserald, 2010: 110).

Isto, no entanto, não fez esvaziar completamente a potência da denúncia da crise ambiental para as lutas decoloniais e anticapitalistas. Desta forma, o ambientalismo também se tornou ferramenta de resistência e re-existência dos povos (Porto-Gonçalves, 2006). Exemplo disto é a emergência de movimentos por justiça socioambiental, que visam denunciar e superar "a distribuição desigual dos benefícios e danos ambientais" (Acserald, 2010: 111), atentando para o racismo na repartição do ônus ambiental, ou seja, do lixo tóxico, da contaminação do solo e da água, da mineração e do uso excessivo de agrotóxicos em algumas regiões do mundo, para alimentar fluxos de finanças do norte global. Observou-se na América Latina um "giro ecoterritorial das lutas" que se dá pela "confluência inovadora entre a matriz indígenacomunitária e o discurso ambientalista" (Svampa, 2016: 147). A noção de território é nuclear aqui, pois ao contrapor a ideia de terra nua, a noção de territorialidade carrega a perspectiva ecológica ressignificando os "recursos naturais" 6 como bens comuns, "que garantem e sustentam as formas de vida em um território determinado" (Svampa, 2016: 149). O conceito de comuns ou bens comuns integra diversas percepções que defendem a necessidade de se manter fora do mercado os recursos cujo valor transcende qualquer tentativa de monetarização. Tem sido relacionado, em âmbito latino-americano, à proposta ética contida nas noções das epistemologias andinas de suma qamañae e sumak kawsay ou bem-viver?

\footnotetext{
6 O termo "recursos naturais" aparece aqui entre aspas porque ele é próprio da lógica de apropriação dos territórios instituída pelo modelo civilizacional capitalista, uma vez que trata a natureza e os bens naturais como matérias primas (a serem extraídos e expropriados destinados a indústria), ou seja, matérias sem valor intrínseco, mas com valor relacionado a sua rentabilidade econômica estabelecido pelo mercado esta entidade da economia capitalista cuja mão é visível e branca (mas isto já é discussão para outro artigo). ${ }^{7}$ Estas noções foram incorporadas pelas constituições da Bolívia e do Equador, respectivamente. Estas constituições representam o movimento do Novo Constitucionalismo Latinoamericano (NCLA), abrindo caminho para a elaboração de uma nova teoria constitucional, com outra concepção de democracia mais adequada à complexa realidade latino-americana (Médice, 2012). Nestas cartas constitucionais ambos Estados se afirmam plurinacionais e interculturais, sendo que a incorporação de epistemologias indígenas no processo constituinte alçou a princípios constitucionais as referidas noções que são traduzidas por bemviver.
} 
O que queremos demarcar é a assimetria do processo compreendido pela globalização, através da expansão do modelo extrativista. Svampa (2011) resume esse processo na tendência dos países do norte a deslocar de suas fronteiras as primeiras fases da atividade extrativa, preocupados com a conservação do meio ambiente local, mas a custa de uma maior deterioração do ambiente a nível global, particularmente dos países do sul cujos territórios são utilizados como fontes de recursos e sumidouros de resíduos. Nesse rol ela inclui desde atividades como a mineração de hidrocarbonetos a céu aberto, a expansão da fronteira florestal, energética e pesqueira até o boom do agronegócio baseado no cultivo de transgênicos e biocombustíveis, associando este novo extrativismo ao que David Harvey (2004) definiu como acumulação capitalista por espoliação. Afinal, trata-se de atividades econômicas baseadas na destruição de territórios.

Esse deslocamento de fronteiras opera através do alargamento simbólico da divisão campo/cidade, rural/urbano. Os territórios alvos do extrativismo costumam ser afastados dos grandes centros urbanos e apresentados segundo um olhar miserabilista que afirma que as populações que lá vivem são atrasadas, com economia estagnada; ou sacrificial, isto é, concebidos como desertos, pois não contêm bens valorizados pelo capital, com exceção dos recursos estratégicos visados (Svampa, 2016). A pressão extrativista também é, assim, racializada. Os territórios dos povos indígenas e comunidades tradicionais, quilombolas, ribeirinhos, e tantos outros não brancos e representativos da diversidade socioterritorial brasileira são o alvo principal. Esses territórios não são necessariamente rurais ou urbanos, eles muitas vezes ocupam um espaço de intersecção - até porque meio rural e meio urbano são completamente interdependentes entre si. Entretanto, os conflitos socioambientais costumam ser tratados como um problema do campo, da ruralidade. Isto faz com que os povos e comunidades tradicionais e originários sejam invisibilizados no contexto das cidades, especialmente através da negativa de seus direitos territoriais em contexto urbano ${ }^{8}$.

${ }^{8} \mathrm{O}$ urbano, em oposição ao rural, sempre ocupou esse lugar do moderno, da 'alta cultura', da civilização. Essa representação, debatida por Lefebvre (2001), vem da filosofia européia e de sua compreensão dicotômica do que é trabalho intelectual e do que é trabalho físico ou material. A cidade, então, é o lugar da subjetividade (filosofia, política, ciência), enquanto o rural é o lugar do original e da natureza. Essas imagens confrontadas criarão um grande simbolismo, que é freqüentemente colocado em oposição antagônica até os dias atuais, e direcionando regulamentações e intervenções sobre o território, bem como definindo quem são os sujeitos, os corpos, permitidos na moderna cidade ou vinculados ao atraso, à miséria, à falta de civilização. 
Por outro lado, o próprio contexto urbano, particularmente o metropolitano, também constrói a partir do discurso do desenvolvimento seu inimigo interno, ou seja, sua face do "subdesenvolvimento". As favelas e seus habitantes racializados são essa "ameaça de subdesenvolvimento", como pontua Jaime Amparo (2018: 4), para quem as políticas da morte são a outra face da política urbana. Há uma complexa interseção entre estética (autoconstrução), formas de vida ("ruralidade" na cidade), e corpos (racializados), que desenha o contorno do permitido e do proibido em prol do "desenvolvimento urbano". Porém, para compreender de que forma o discurso desenvolvimentista é positivamente avaliado e a espoliação de territórios com o genocídio de povos é naturalizada, precisamos falar da mais potente ferramenta do capitalismo/ colonialismo: o racismo.

\section{Breves notas sobre a invenção da raça e a naturalização da diferença}

O conceito de raça será central ao pensamento europeu como fundamento do colonialismo, especialmente ao apresentar uma não contradição entre o cristianismo e, posteriormente, o iluminismo francês e inglês ${ }^{9}$ e a colonização. Este conceito, entretanto, continua atual (e se atualizando), ao servir como um marcador da diferença, que precisa de modelos duais - desenvolvido e subdesenvolvido. Se considerarmos o colonialismo europeu e seu discurso de levar a civilização a lugares selvagens, a continuação dessa ideologia está muito presente nos entendimentos e práticas em torno da ideia de desenvolvimento (que não está isenta de ideologias colonialistas nem é racialmente neutra), como aponta Goldberg (2002). As dualidades ${ }^{10}$ tão presentes do discurso colonial - campo-cidade, civilizado-incivilizado, legal-ilegal - tem a raça como elemento definidor da diferença e no Direito a instituição privilegiada (Bertúlio, 1994) de delimitação dos contornos da normalidade. Por outro lado, o controle do espaço

\footnotetext{
${ }^{9}$ Como pontua Silvio Almeida "a raça emerge como um conceito central para a aparente contradição entre a universalidade da razão e o ciclo de morte e destruição do colonialismo e da escravidão possam operar simultaneamente como fundamentos irremovíveis da sociedade contemporânea" (Almeida, 2019: 28).

${ }^{10}$ O Pensamento eurocêntrico, na crítica de Anibal Quijano, centra-se em três pontos fundamentais, sendo: (a) uma articulação peculiar entre dualismo (capital-precapital, Europa-não-Europa, civilizado-primitivo, tradicional-moderno, etc.) e um evolucionismo linear, unidirecional, de algum estado de natureza para sociedade europeia moderna; (b) a naturalização das diferenças culturais entre grupos humanos por meio de sua codificação com a ideia de raça; e (c) a realocação distorcida-temporal de todas essas diferenças, realocando não-europeus no passado (Quijano, 2000: 552-53).
} 
(demografia e propriedade) será o onde da reprodução colonial do poder e de desumanização.

Nesse processo os denominados recursos e a terra são expropriados, os colonizados ${ }^{11}$ tornam-se corpos sem-terra e, assim, sem capacidade para a autonomia e autodeterminação (Maldonado-Torres 2016: 17). O não reconhecimento da humanidade do outro (negros e indígenas) por uma concepção monoestética do que é o humano (Wynter, 2003: 291), levou a sua objetificação e a apropriação de suas terras marcadas como res nullius. $\mathrm{O}$ argumento de Sylvia Wynter em relação à conquista de 1492 é como o homem (o europeu cristão branco) teve que ser ontologicamente descrito em relação ao novo mundo e seus habitantes, bem como representado fisicamente em esquemas corporais de diferenciação. A inabitabilidade da terra (Novo Mundo - inimaginável para os europeus, categorizada como res nullius) tinha que ser mapeada para se transformar em recurso rentável, tinha que ser habitável. Para isso, geografias desiguais foram colocadas em prática para definir a diferenciação social do anormal para o "modo de vida normal" (McKittrick, 2006). A normalidade é sempre construída em oposição ao seu contrário, de modo que o inabitável deve permanecer para que o habitável possa ser ${ }^{12}$.

Frantz Fanon (2008), por outro lado, irá argumentar que os racializados foram excluídos da dialética do Eu e o Outro, ocupando um outro lugar que é a zona da não existência, ou a zona do não ser, onde a lógica é governada pela violência, apropriação e expropriação. Na zona do não ser vigora a não ética da guerra: "a colonialidade do ser se refere a normalização de eventos extraordinários que tomam lugar na guerra. Enquanto na guerra há violação corporal e morte, o inferno do mundo colonial a morte e a violação ocorrem como realidades e ameaças diárias" (Maldonado-Torres, 2007: 148). A normalidade de nossa realidade colonial-racista é que a experiência da morte

\footnotetext{
${ }^{11}$ Maldonado-Torres, em suas 10 teses sobre a colonialidade, vai dizer, na tese 4 que "os efeitos imediatos da modernidade/colonialidade incluem: a naturalização do extermínio, expropriação, dominação, exploração, morte precoce e as condições que são piores que a morte, como a tortura e o estupro" (2016, p. 16, tradução nossa).

${ }^{12}$ Como a criação do 'Homem' é simultânea à invenção do Outro, a super-representação do 'Homem' em termos geográficos se relaciona com a forma como as duas representações são construídas uma em relação à outra. A luta contra a super-representação do homem desafia a naturalização pelos processos capitalistas globais de estigmatização dos "sem-teto, subdesenvolvidos, desempregados, encarcerados" (McKittrick 2006, 126), aqueles lugares inabitáveis e habitáveis. Aqueles 'outros' estigmatizados - corpos / lugares ilustram a super-representação das geografias do 'Homem' que são produzidas enquanto se apagam desapropriações e despejos. O projeto colonial de criar 'alteridade' era intimamente relacionado à criação de diferenciações espaciais.
} 
pelas pessoas racializadas não é uma experiência excepcional, mas sim uma experiência cotidiana, como diz Maldonado-Torres, é "parte constitutiva do suposto mundo normal" (2007: 148). O autor reflete como o contexto de guerra que é excepcionalmente pensado, para esses sujeitos racializados é da essência mesma do mundo colonial antinegro, e dialogando com João Vargas (2017) também anti-indígena a partir da lógica do genocídio.

Ao mesmo tempo em que temos a descrição da lógica que governa a zona do não ser, temos também as lógicas que irão governar as zonas do ser, ou as zonas civilizadas. Essas devem se manter puras e para tanto é necessário evitar a contaminação por corpos/culturas inferiores. Homi Bhabha (1994) teorizou esse medo da contaminação como uma fantasia do colonizador com o mito da origem ou do desejo da pureza de origem (cultura pura, raça pura). Essa pureza é ameaçada pelas diferenças articuladas como raça, cor, cultura, que são sempre negativas no discurso colonial. Veremos como o Direito é a instituição privilegiada pois disciplina a normalidade da vida social através dos comandos do dever ser e do proibido que irão informar a necessidade de controlar a contaminação social através do controle das culturas/corpos incivilizados, como punir ou exterminar os corpos que ameaçam os desejos de uma nação pura (leia-se branca).

Como argumentado por David Goldberg (2002), a regra racial que posiciona os europeus como superiores aos não europeus vem de duas tradições. A primeira, a concepção naturalista, foi dominante do século XVII ao XIX. A outra, que, segundo ele, foi negligenciada, é a concepção historicista, em que a afirmação é de que "aqueles que não são brancos não são inerentemente inferiores, mas imaturos de desenvolvimento, historicamente ainda não são capazes de se autogovernar" (Goldberg, 2002: 82), precisam da orientação da Europa benevolente. Ele argumenta que, mesmo que a forma naturalista seja mais cruel (racismo aberto como o apartheid), a histórica é ambígua, hipócrita e tende a esconder os pressupostos de inferioridade. Diferente do naturalismo, onde as pessoas são restringidas em espaços congelados no tempo, no historicismo elas habitam um tempo pré-moderno, mas ainda por vir. Então, o sujeito colonial não branco é inserido no mercado global com promessas de desenvolvimento e igualdade (Goldberg, 2002), mas o custo da expropriação e do extermínio é revertido para as próprias comunidades como consequência de sua própria imaturidade. 


\section{O medo do outro: racismo e desenvolvimento urbano no Brasil}

Alguns autores ${ }^{13}$ no contexto brasileiro abordaram de que forma os diversos processos de reestruturação ou modernização das cidades foi historicamente relacionado a discursos que constroem a imagem do progresso à antítese de uma cidade que existe, classificada como subdesenvolvida e que contamina o desejo de pureza. Exemplos trazidos por Vera Malaguti Batista, ao analisar jornais no período inicial da República e depois os dos anos 1990, mostram-nos como as narrativas mantiveram-se ao longo do século. Segundo a autora, "a ocupação do espaço público pelas classes subalternas produz a fantasia de pânico do 'caos social', que se ancoram nas matrizes constitutivas da nossa formação ideológica" (Batista, 2003:34). O medo branco da ocupação da cidade pelos negros "permeou a corte imperial após a Revolta dos Malês em 1835, assombrou a nação após a abolição da escravidão e a proclamação da República. Vagou nas águas da Revolução de 30, no suicídio de Getúlio, no golpe de 64 e nas conjunturas eleitorais de 1994 e 1998" (Batista, 2003: 35).

Dessa forma, o projeto urbano construído para o Brasil, especialmente a partir da República, tinha como cerne o exercício do biopoder ${ }^{14}$, ou seja, exercer o poder demográfico sobre o espaço público (Goldberg: 2002) a partir da lei racial. David Goldberg, em sua obra o Estado Racial, irá pontuar que a raça é apresentada desde o início como um problema urbano. Segundo ele, "a preocupação com a raça tornou-se uma questão de natureza e disciplina, estética e moralidade do espaço público, como quem pode ser visto e onde e como" (2002: 173, tradução nossa). Goldberg indica que o estado racial regula e codifica na perspectiva de perpetuar o poder e privilégio branco (propriedade, costumes, etc) ${ }^{15}$.

\footnotetext{
${ }^{13}$ Obras como a "Cidade Febril" de Sidney Chalhoub (2017), "Onda negra, Medo Branco" de Maria Celia Azevedo (1987) e o "Medo da Cidade do Rio de Janeiro" de Vera Malaguti (2003), trazem os discursos em torno da ideia de contaminação e o pânico das elites.

${ }^{14}$ Utilizamos aqui as noções de biopoder e biopolítica a partir da leitura de Hardt e Negri (2016) do conceito de biopolítica de Foucault. Os autores argumentam que embora biopolítica costume ser compreendida como somente a agência de um poder disciplinador sobre todas esferas da vida, Foucault também salientava em seus escritos o aspecto de resistência da biopolítica. Todo poder gera resistência, de modo que as duas forças estão atreladas uma à outra, ou seja, são a mesma. Para diferenciar estes aspectos opostos da biopolítica eles propõem tratar este poder disciplinador, opressivo, como biopoder e a resistência como biopolítica.

${ }^{15}$ Goldberg vincula as mudanças no interesse acadêmico da sociologia urbana, mudando das questões mais biológicas para as culturais em torno da raça, juntamente com o racismo visto como preconceito individual. Também o urbanismo e a preocupação com a pobreza e a urbanidade, civilidade.
} 
O controle do território, nesse sentido, atendia/atende a dois objetivos, manter a cidade 'branca' da civilidade e modernidade, gerida pela 'técnica' do planejamento, e controlar esse mesmo espaço da contaminação dos sujeitos 'contagiosos' em sua incivilidade. Segundo Vera Malaguti:

Homogeneizar essa heterogeneidade é o esforço de formação de sociabilidade urbana numa perspectiva de ordem e civilidade que na verdade traduziriam 'um projeto de poder e um estilo de dominação' que viriam a 'estetizar o cotidiano, impor uma ordem minuciosa que regulasse todas as esferas da existência e forjar o decoro público'. Pechman analisa a inexorável urbanização da capital do Império no sentido da atualização dos códigos de mando e de obediência (Batista, 2003: 215).

A relação do medo branco à contaminação desses corpos racializados, seja pela insurreição, mas muito ilustrativa na própria ocupação do espaço público, demonstra a disputa da cidade por controle, poder, através de uma linha racial. Malaguti comenta que o estranhamento com fenômenos como os rolezinhos ${ }^{16}$ demonstra que "é como se houvesse um zoneamento invisível, inconsciente, em que os deslocamentos humanos causassem mal-estar e perplexidade" (Batista, 2003: 108). Diríamos que esse zoneamento pode ser invisível para os brancos, porque para os corpos racializados ele é real e bem visível, apresenta-se pela segurança pública ou privada que controla a mobilidade das pessoas na cidade.

Frantz Fanon (2008) diz que o negro é hipervisível no mundo branco (universidade, shopping, judiciário), ainda mais se ele está ali disputando a tal igualdade prometida e não em posições que ele deve ocupar no mundo branco. A periculosidade, então, vai estar associada a esse negro/negra "que não sabe seu lugar", como nos provoca Lélia Gonzalez (1988). Esses são conformados no lugar do criminoso, pois é aquele que rompe a ordem do sistema racista, por isso é tão importante a diferenciação, do trabalhador (que estaria em seu lugar - submisso) e do bandido (o corpo insubmisso - que não sabe seu lugar). Mas quem determina essa qualificação não é o sujeito, mas a ordem racial que controla os corpos e o espaço.

\footnotetext{
${ }^{16}$ Jovens pobres, majoritariamente negros, organizaram-se via redes sociais para passear em shoppings de áreas nobres de metrópoles brasileiras, o que se chamou de rolezinho. 0 pânico social provocado por esse transpasse repercutiu fortemente nos meios de comunicação e provocou grande repressão policial em nome da ordem pública. Veja em <https://www1.folha.uol.com.br/cotidiano/2013/12/1386132-mesmosem-crimes-rolezinho-causou-panico-e-levou-policia-a-shopping-de-guarulhos.shtml>, acesso em 29.01.2020.
} 
Os povos indígenas, nessa perspectiva, foram excluídos da cena urbana, confinados a um lugar distante e idílico. A invisibilidade dos indígenas na cidade, ou mesmo nos contextos regionais sudeste-sul, também os inserem na política da morte, entre genocídio e etnocídio. O recente incidente em que um Procurador de Justiça disse em ato público que a escravização de negros só ocorreu porque os indígenas não gostam de trabalhar ${ }^{17}$, explicita como o racismo no Brasil se constrói, e se atualiza, também sobre estereótipos indígenas negativos, como sujeitos não aptos ao trabalho ou como ocupando terras de forma improdutiva, vivendo na pobreza ${ }^{18}$. Ideias estas que serão sempre articuladas a partir de um ideal valorativo economicista, de matriz capitalista, como são os próprios indicadores de desenvolvimento.

Assim, o corpo racializado é lido como uma marca de subdesenvolvimento, ou uma ameaça de subdesenvolvimento, como diz Jaime Amparo (2018) e Goldberg (2009), que é preciso esconder ou controlar, particularmente quando se quer vender uma imagem da cidade como moderna, elevá-la a cidade global, afinal o racializado é a antítese do moderno. Não é por acaso que as imagens do subdesenvolvimento que vem às nossas mentes nunca são racialmente neutras, nem os corpos nem os espaços. Assim, como argumentado em outro momento, a "política urbana ao tentar ser racialmente neutra também beneficia a perpetuação da linha racial" (Coelho e Marques 2019: 141).

Levar o desenvolvimento à lugares subdesenvolvidos virou um discurso progressista, cuja base é colonial e a ferramenta mais potente, o racismo. Racismo, contudo, não se resume a um marcador de cor (mesmo que esse seja o elemento mais evidente), ele engloba as diversas formas de ver o mundo, de viver e pensar e, particularmente, de articular o sentido de vida boa ou bem-estar. Se estes sentidos são antagônicos ao avanço do capitalismo, os estereótipos raciais negativos serão sempre mobilizados para colocar esses povos perigosos no passado, no atraso e na contramão do desenvolvimento.

\footnotetext{
17Disponível em <https://g1.globo.com/pa/para/noticia/2019/11/26/procurador-de-justica-do-para-dizque-problema-da-escravidao-no-brasil-foi-porque-indio-nao-gosta-de-trabalhar.ghtml>

${ }^{18} \mathrm{O}$ atual debate sobre a exploração de recursos naturais em terras indígenas reacende preconceitos em torno dos modos de vida indígena no país, conferir em:https://www12.senado.leg.br/noticias/especiais/especial-cidadania/congresso-e-palco-de-debatesobre-o-papel-dos-indios-na-sociedade.
} 
5. Direito à cidade contra o desenvolvimento: o jurídico nas utopias possíveis

Lefebvre (2001) coloca as utopias como centrais para provocar a transformação das formas de produzir conhecimento, de pensar a cidade. Dizia da necessidade de introduzir o conhecimento na utopia. As utopias lefebvrianas são utopias possíveis, pois são consideradas experimentalmente. Essa ideia de um pensar prático colado à realidade e testado por ela. De modo que convida à reflexão sobre os critérios que garantem o sucesso das experiências. "Quais tempos, quais ritmos de vida cotidiana se inscrevem, se escrevem, se prescrevem nesses espaços 'bem-sucedidos', isto é, nesses espaços favoráveis a felicidade? É isso que interessa" (Lefebvre, 2001: 110). Os autores Luiz Antonio Simas e Luiz Rufino (2019), por sua vez, provocam-nos a ver e ouvir os caboclos, a experimentar a cidade terreiro. A cidade que é ao mesmo tempo morte e vida, é metrópole e aldeia, é memória ancestral de amor e dor. A diversidade do cotidiano, das trajetórias, as brechas do passado e do futuro, tudo permeia a multiterritorialidade urbana e seus conflitos. Os tambores não se calam, as linhas continuam a serem cruzadas, mesmo que tudo tenha um custo de sangue, gravado na carne. Assim,

o cotidiano da cidade reverbera as ambivalências, a dimensão encruzada do ser lançado aos ataques da empresa contrária à vida e a incessante busca na produção de presenças, táticas, formas de sobrevivência inscritas na criatividade, transgressão e remontagem dos cacos existentes (Simas \& Rufino, 2019: 77-78).

Querer fazer um pensamento aberto é correr riscos. Elaborar costuras e juntar perspectivas geralmente analisadas em apartado é ousado. Mas entendemos como elementar das utopias experimentais. Estabelecida e situada nossa compreensão e crítica do desenvolvimentismo, resta apresentar o que seria esse direito à cidade contra o desenvolvimento. Esta é uma operação que temos que realizar cuidadosamente, já que, no contexto do direito urbanístico brasileiro o direito à cidade costuma ser compreendido como um elemento necessário para o desenvolvimento urbano. Isto se apreende do texto constitucional.

A Constituição da República Federativa do Brasil de 1988 é um marco na história constitucional brasileira, caracterizada como analítica e dirigente, representando a retomada do processo democrático após 20 anos de ditadura civil-militar. É uma constituição desde o preâmbulo comprometida com o desenvolvimento. O capítulo da 
Política Urbana, aberto pelo artigo 182, estabelece as diretrizes da Política de Desenvolvimento Urbano, cujo objetivo é “ordenar o pleno desenvolvimento das funções sociais da cidade". Não se trata de negar a importância e a conquista histórica que significou inserir a questão urbana no âmbito das garantias constitucionais. Tampouco, desmerecer o fato de que se tratou de capítulo resultante de proposta de lei de iniciativa popular da constituinte, representada pela capacidade mobilizatória do Fórum Nacional da Reforma Urbana (Maricato, 2013). Trata-se, entretanto, de atentar para a presença do paradigma do desenvolvimento na norma constitucional.

Em alguns casos, produz-se uma tensão entre o desenvolvimentismo e a Constituição. Há que se destacar que o núcleo dos direitos e garantias fundamentais é a "dignidade da pessoa humana", valor que muitas vezes é oposto ao crescimento e o progressismo pregado pelo desenvolvimento. No entanto, o coração das tensões entre a norma constitucional e o desenvolvimento está, na nossa perspectiva, no reconhecimento e garantia dos chamados direitos culturais nos artigos 215 e 216 . Ao afirmar que os modos próprios de criar, fazer e viver dos diversos povos e matrizes culturais que compõem a sociedade brasileira fazem parte do seu patrimônio cultural e por isso, devem ser defendidos, valorizados, promovidos e garantidos ${ }^{19}$, a Constituição Federal de 1988 abre uma brecha (Walsh, 2014) que pode ser operada no sentido de tensionar a colonialidade e o racismo presentes no próprio direito.

A tensão provocada pela incidência do paradigma do desenvolvimento na norma constitucional gera efeitos e se apresenta em todo o texto da Constituição. Entretanto, essa imagem urbana do desenvolvimento, já referida anteriormente, que relaciona o alcance do status desenvolvido com a proliferação de um modelo específico de cidade, faz com que o núcleo da norma constitucional para a cidade seja o desenvolvimento urbano.

Quanto ao direito à cidade, ele costuma ser aferido da noção constitucional de função social da cidade. Não há espaço aqui para adentrarmos a questão da influência do funcionalismo na disciplina jurídica, porém, cabe retomar o que é este direito à cidade vinculado à função social. Trata-se, sucintamente, da realização de algumas premissas: garantia a todos habitantes da cidade de acesso à bens e serviços públicos;

\footnotetext{
${ }^{19}$ Junto com o direito à livre manifestação religiosa, por exemplo, é um garante para os povos de terreiro. 0 reconhecimento e a garantia dos direitos territoriais de povos indígenas e quilombolas, que é lida combinada com os direitos culturais, também compõe esse núcleo.
} 
garantia de acesso à moradia digna; regulação e controle democrático do uso do solo urbano; controle social e participação democrática da gestão urbana (Jardim, 2011). Nesse sentido, vincula-se o direito à cidade ao exercício da cidadania e ao acesso à terra urbana (Fernandes, 2001). Entretanto, enquanto conceitos abertos, sua significação e posterior concretização na prática jurídica e da política pública não escapam a hierarquização de pessoas/ lugares/ saberes a partir da ideia de civilização e progresso. Assim, a face repressora do direito estatal, seja pela política urbana racista, ou pela própria política de segurança pública seletiva e legal, faz com que o reconhecimento de cidadania ${ }^{20}$ esteja restrito a um aspecto formal e institucional.

O que referimos aqui é o modo como o exercício da cidadania ${ }^{21}$, pretensamente reconhecido constitucionalmente a todos, é constantemente negado através da combinação entre política urbana e política de segurança pública, que se mostram como duas caras de uma mesma moeda quando a política urbana é a governança neoliberal (Amparo, 2018). Assim, no exemplo já trazido dos rolezinhos dos jovens habitantes das favelas e periferias, ou quaisquer ocupações do espaço público das cidades brasileiras pela juventude negra e pobre em busca de lazer, mobiliza-se o medo branco e veta-se a cidadania. O caso recente da repressão policial em um baile funk na favela de Paraisópolis em São Paulo, que resultou na morte de 9 jovens, entre 14 e 23 anos 22 , é outro exemplo de como a violência é a regra na zona do não ser e o controle espacializado. A política de Estado reservada a esses jovens contrasta com a cidadania prometida, expondo a face do Estado Racial e a falácia da igualdade. Evidenciam-se, assim, os limites da compreensão do direito à cidade circunscrito pela noção jurídica de cidadania.

\footnotetext{
${ }^{20} \mathrm{~A}$ cidadania enquanto conceito jurídico sempre foi um conceito restrito. A maior parte da população nunca esteve incluída no conceito de cidadão, como nos argumenta Dora Bertúlio (1994). Por exemplo, analfabetos só passaram a ter direito a voto na Constituição de 1988, excluindo primordialmente negros e indígenas dos "direitos" decorrentes desse contrato social.

${ }^{21}$ Para aqueles que estão na zona do não ser, ou do outro lado da linha abissal, a lógica que governa é a da morte, como já mencionado acima. A tensão entre regulação e emancipação somente se daria do lado 'humano' da linha, enquanto abaixo da linha a lógica que governa é da violência e expropriação(Grosfogue 2016). Isso coloca uma problemática para o Direito que, como parte do mecanismo de controle e opressão, de origens coloniais, teria pouco a oferecer como ferramenta emancipatória. Contudo, nas trincheiras da disputa do cotidiano, sem jamais ser um fim em si mesmo ou almejar ser a linguagem da transformação social, o Direito ainda se apresenta como campo de disputa, como ferramenta dentre muitas, como linguagem do poder onde se mobiliza as contradições do próprio Estado Moderno.

${ }^{22} \mathrm{O}$ caso foi divulgado pela mídia alternativa e pela comunidade como o Massacre de Paraisópolis, e ocorreu na madrugada do dia 30/11 para o dia 1/12/2019, para maiores informações ver: https://ponte.org/o-quese-sabe-do-massacre-de-paraispolis/. Acesso em: 11/12/2019.
} 
O outro lado dessa moeda é a própria lógica da expropriação e apropriação dos territórios ocupados pelos povos racializados que, ao estarem sempre no "caminho do desenvolvimento", sujeitam-se aos constantes processos de desterritorialização e reassentamentos. Trajetórias e vidas transformam-se em terra rasada para dar lugar aos novos esforços de desenvolver as metrópoles, completando o ciclo homogeneizador, planificado e estéril da ordem capitalista mundial.

Assim, o direito urbanístico voltado ao desenvolvimento urbano se adequa as novas tendências do modelo do planejamento urbano estratégico, que importa a lógica e os preceitos da gestão empresarial para a administração da cidade centrada no princípio da competitividade. Conforme Otília Arantes (2013), a cidade-negócio ou cidade-empresa está ancorada a uma "pseudomercadoria": o solo. Uma vez que a terra urbana torna-se alvo primordial da especulação capitalista, sobressaindo o valor de troca, esta passa a ser a finalidade mesma da cidade: atrair investimentos. Isto, a autora resume como a ideia da cidade como máquina de crescimento (growth machine) (Arantes, 2013). A cidade como máquina de crescimento é lida aqui como a expressão máxima da aplicação do desenvolvimentismo na razão do urbano.

Onde está o direito à cidade neste contexto? Enclausurado nesta cidadania formal e consensual dos planejamentos estratégicos? Preso a uma concepção de cidade que ignora a realidade das cidades brasileiras - desconhece a linha racial, quer varrer a autoconstrução da paisagem urbana, ignora a realidade das pequenas e médias cidades, desconsidera a relação entre rural e urbano. Seria isto? Ou exatamente o contrário? Lefebvre situa a reivindicação do direito à cidade no contexto do surgimento de direitos concretos desde a pressão das massas, que "vêm completar os direitos abstratos do homem e do cidadão inscritos no frontão dos edifícios pela democracia" (2001: 116). 0 autor continua que "o direito à cidade se afirma como um apelo, como uma exigência" (Lefebvre, 2001: 117), só podendo ser formulado como direito à vida urbana. O urbano como lugar do encontro da priorização do valor de uso do espaço, em detrimento do valor de troca.

O direito à cidade precisa ser descolado do desenvolvimento para que este sentido de vida urbana não seja previamente dado, como fórmula imposta. O sentido de vida urbana tem que ser aberto para que possa ser preenchido desde as experiências, as realidades e as necessidades das cidades brasileiras, ou melhor, das pessoas que as habitam - lembrando sempre que sociedade é espaço (Haesbaert \& Porto-Gonçalves, 
2006). Há aí um problema estrutural de negativa de status de cidadania/humanidade que opera nuclearmente através do racismo e da colonialidade do poder, e por meio do direito. O nosso argumento é de que enquanto não desassociarmos a potência do direito à cidade da lógica do desenvolvimento urbano, seremos incapazes de superar essa estrutura.

Não se trata de negar, no entanto, toda possibilidade de disputa interna ao direito urbanístico, ou mesmo de advogar que não se apliquem mais os instrumentos da política urbana ou que cessem de disputar seus limitados espaços de participação democrática, porém, de que se mudem as chaves de leitura desses processos. É necessário visibilizar os mecanismos violentos, racistas e coloniais do desenvolvimento urbano para que a luta política não seja por mais desenvolvimento, mas por alternativas ao desenvolvimento. Que as utopias possíveis sejam aquelas que visualizam e experimentam transições ao pós-desenvolvimento.

\section{Considerações finais}

A ilusão desenvolvimentista (Svampa, 2011) perseguida pelas nações latinoamericanas, aqui pensamos especialmente o Brasil, aponta para um caminho do urbano e de um modelo específico de cidade. Países desenvolvidos são países urbanizados. As cidades cartão-postal contemporâneas como Paris, Londres e Nova York competem e se igualam, ao promover planejamentos estratégicos que contam com monumentos e prédios erguidos pelos mesmos arquitetos da moda (Rolnik, 2015). Por outro lado, os países latino-americanos apostam no caminho da extração e produção de commodities, ou seja, no fortalecimento de um modelo agrário exportador, para chegar lá. Essa combinatória de elementos aparentemente opostos vai resultar numa experiência urbana outra de modo que no contexto brasileiro cada vez perde mais sentido essa divisão estrita entre rural e urbano.

Primeiro porque ela contribui para a invisibilização do próprio paradigma extrativista, da percepção de que a urbanização brasileira, isto é, a concentração da maioria da população nas cidades não está em oposição ao fortalecimento de um capitalismo agroexportador - até porque esse modelo agrário se faz de um mundo rural sem gente, sendo que os próprios representantes do agrobusiness reforçam o 
estereótipo vazio, apenas campos verdes de soja transgênica e colheitadeiras como se vê em qualquer edição do programa televisivo Globo Rural. Sem gente, sem indígenas, sem quilombolas, sem ribeirinhos, sem pescadores artesanais. Desta forma, o ornitorrinco de Francisco de Oliveira (2013) é simbolizado por este animal estranho dificilmente classificável, porque não segue a prescrição eurocentrada, porque nem pode seguir. Colocando em questão mesmo o entendimento de Lefebvre (2001) da relação intrínseca formando um binômio da industrialização-urbanização. ornitorrinco, reprimariza-se e entrega-se a voragem das finanças e da destruição pela extração.

Segundo, a insistência nesse abismo entre urbano e rural impossibilita a própria compreensão do que é o urbano no Brasil. O que queremos dizer é que o urbanismo brasileiro é muito baseado nas megalópoles, especialmente do sudeste, perdendo em compreensão das múltiplas experiências urbanas brasileiras. Dados do IBGE de 2019 demonstram que as cidades que mais crescem atualmente são as médias, entre 100 mil e 1 milhão de habitantes ${ }^{23}$. Por exemplo, como pensar o fenômeno urbano a partir da cidade de Altamira, no Pará, em que o boom populacional ocasionado pela construção da hidrelétrica de Belo Monte gerou uma série de conflitos? Que espaço há em instrumentos como os planos diretores para as demandas territoriais das comunidades tradicionais pesqueiras cujos territórios também incluem as águas? Essas questões exemplificadoras são apenas um convite a repensar os contornos e o conteúdo de um direito urbanístico. Também se colocam com o objetivo de apresentar nosso argumento central neste artigo: descolar a noção de direito à cidade da ideia de desenvolvimento urbano.

O conceito de desenvolvimento urbano aplica à cidade a mesma lógica de evolução linear do desenvolvimento econômico. Desenvolver uma cidade significa adequá-la a um padrão previamente determinado, significa incluí-la em um certo circuito de trocas, torná-la atrativa para investimentos, embelezá-la segundo um único padrão de beleza. Isto em geral é feito às custas dos que vivem na cidade, alterando drasticamente seus modos de vida, através de despejos, reassentamentos, mudanças drásticas de paisagem, mas especialmente controle dos corpos e manifestações que

${ }^{23}$ Os dados são das Estimativas de População do IBGE, vinculados em: https://agenciadenoticias.ibge.gov.br/agencia-noticias/2012-agencia-de-noticias/noticias/25280-um-emcada-tres-brasileiros-mora-em-48-municipios-com-mais-de-500-mil-habitantes, acesso em 10/12/2019. 
maculam a imagem do desenvolvimento. Contra esse biopoder representado pela imposição do desenvolvimento urbano, resistem e r-existem corpos indisciplinados na cidade criando espaços, culturas, gritando sua presença.

Descolar o conceito de direito à cidade da noção de desenvolvimento urbano é uma operação necessária para superar a incidência da colonialidade do poder e do racismo na política urbana e no direito urbanístico. Separado do desenvolvimento, o direito à cidade pode exercer sua potência mobilizatória e analítica. E assim retomar o sentido de exigência, presente na noção iniciada por Lefebvre (2001), bem como sua relação com um pensamento tendente a abertura. Neste sentido, o direito à vida urbana implícito no direito à cidade, não pode ser resumido a um modelo de desenvolvimento e de cidade. O conteúdo deste direito à vida urbana tem que estar sempre aberto aos sentidos que serão dados desde cada experiência na cotidianidade própria da diversidade sócio-territorial brasileira.

A estética dessas cidades é também aquela da autoconstrução, é a estética que conta uma história, que descreve trajetórias, e essas levaram a milhões de pessoas a construírem suas casas e suas comunidades. Precisamos deixar de olhar para essa estética como algo transitório, passageiro, que irá se desenvolver para grandes torres de apartamentos. Essa utopia de alguns é o pesadelo de muitos, e se iremos compreender o direito à cidade como ferramenta mobilizadora da possibilidade de construção de cidades, precisamos que todas as formas sejam cidade. Isso, por certo, não dilui o conflito de uma cidade erguida através da segregação, de muros do apartheid produzidos pela linha racial, de expropriação e apropriação. $O$ que é negativo em nossas cidades não é essa multiplicidade de trajetórias que a conformam, mas os efeitos nefastos do desenvolvimento urbano contra a cidade.

\section{Referências}

ACSERALD, Henri. "Ambientalização das lutas sociais: o caso do movimento por justiça ambiental”. In: Estudos Avançados, n. 24, v. 68. 2010.

ALMEIDA, Silvio. Racismo Estrutural. São Paulo: Pólen, 2019.

ALVES, Jaime Amparo. The Anti-Black City: Police Terror and Black Urban Life in Brazil. Minneapolis; London: University of Minnesota Press, 2018. 
ARANTES, Otília Beatriz Fiori. "Uma estratégia fatal: a cultura nas novas gestões urbanas". In: A cidade do pensamento único: desmanchando consensos. ARANTES, Otília. VAINER, Carlos. MARICATO, Ermínia (Orgs). Petrópolis: Vozes, 2013.

BATISTA, Vera Malaguti. O Medo Na Cidade Do Rio de Janeiro: Dois Tempos de Uma História. Rio de Janeiro: Editora Revan, 2003.

BHABHA, Homi K. The Location of Culture. London and New York: Routlege, 1994.

BERTÚLIO, Dora Lucia de Lima. Direito e Relações Raciais: Uma Introdução Crítica Ao Racismo. Rio de Janeiro: Lumen Juris, 2019.

- "Considerações Sobre a Discriminação de Raça e Gênero Na Sociedade Brasileira," 1-50, 1994.

ESPINOSA-MIÑOSO, Yuderkys. 2014. “Una Crítica Descolonial a La Epistemología Feminista Crítica." El Cotidiano, 7-12.

FANON, Frantz. Pele Negra MáscarasBrancas. Salvador: EDUFBA, 2008.

FERNANDES, Edesio. Direito Urbanístico e política urbana no Brasil. Belo Horizonte: Del Rey, 2001.

GOLDBERG, David Theo. The Racial State. Malden, Mass: BlackwellPublishers, 2002.

GONZALEZ, Lélia. Por Um Feminismo Afro-Latino-Americano. Caderno de Formação Política Do Círculo Palmarino, 12-20, 2011.

(jan/jun): 69-82, 1988.

"A Categoria Político-Cultural de Amefricanidade". Tempo Brasileiro 92/93

GUDYNAS, Eduardo. “Debates sobre el desarrollo y sus alternativas en América Latina: Una breve guia heterodoxa". In: Más Allá del Desarollo: Grupo permanente de Trabajo sobre Alternativas al Desarrollo. LANG, Miriam. MOKRANI, Dunia (coord). Quito: AbyaYala, Fundação Rosa Luxemburgo, 2011.

GROSFOGUEL, Ramon. "What Is Racism?" Journal of World-Systems Research, 22 (1): 915., 2016.

HAESBAERT, Rogério. PORTO-GONÇALVES, Carlos Walter. A nova des-ordem mundial. São Paulo: UNESP, 2006.

HARVEY, David. "O "novo" imperialismo: acumulação por espoliação". In: PANITCH, Leo; LEYS, Colin (ed.). Socialistregister 2004: o novo desafio imperial. São Paulo; Buenos Aires: CLACSO, 2006. p. 95-125.

JARDIM, Zélia Leocádia da Trindade. Regulamentação da política urbana e garantia do direito à cidade. In: COUTINHO, Ronaldo. BONIZZATO, Luigi. Direito da cidade: novas 
concepções sobre as relações jurídicas no espaço social urbano. Rio de Janeiro: Lumen Juris, 2011.

LANG, Miriam. Alternativas ao desenvolvimento. In: Descolonizar o imaginário: debates sobre o pós-extrativismo e alternativas ao desenvolvimento. DILGER, Gerhard; LANG, Miriam; PEREIRA FILHO, Jorge (Orgs). São Paulo: Fundação Rosa Luxemburgo, 2016.

LEFEBVRE, Henri. O Direito à Cidade. São Paulo: Centauro, 2001.

. Revolução Urbana. Belo Horizonte: Editora UFMG, 2008.

MALDONADO-TORRES, Nelson. "Outline of Ten Theses on Coloniality and Decoloniality". Disponível em: http://frantzfanonfoundationfondationfrantzfanon.com/article2360.html, 2016.

. "Sobre La Colonialidad Del Ser: Contribuiciones Al Desarrollo de Un Concepto". In: El Giro Decolonial. Reflexiones Para Una Diversidad Epistémica Más Allá Del Capitalismo Global. CASTRO-GÓMEZ, Santiago; GROSFOGUEL, Ramón (ed.), 127-67. Bogotá: Siglo del Hombres Editores, 2007.

MARICATO, Erminia. O impasse da política urbana no Brasil. Petrópolis: Vozes, 2014.

. Brasil, cidades: alternativas para a crise urbana. Petrópolis: Vozes, 2013.

MARINI, Ruy Mauro. América Latina, dependencia y globalización. México, D. F.: Siglo XXI Editores; Buenos Aires: CLACSO, 2015.

MCKITTRICK, Katherine. Demonic Grounds: Black Women and the Cartographies of Struggle. Minneapolis: Universityof Minnesota Press, 2006.

MÉDICE, Alejandro.La constitución horizontal: teoría constitucional y giro decolonial. San Luis de Potosí: Universidad Autónoma de San Luis Potosí, 2012.

MOURA, Clóvis. Sociologia Do Negro Brasileiro. 2nd ed. São Paulo: Perspectiva, 2019.

NASCIMENTO, Abdias do; FERNANDES, Florestan; SOYINKA, Wole; NASCIMENTO, Elisa Larkin. $O$ genocídio do negro brasileiro: processo de um racismo mascarado. São Paulo: Editora Perspectiva S.A., 2016.

NEGRI, Antonio; HARDT, Michael. Bem-estar comum. Tradução Clóvis Marques. Rio de Janeiro: Record, 2016.

OLIVEIRA, Francisco de. "O ornitorrinco". In: OLIVEIRA, F. Crítica à razão dualista: o ornitorrinco. São Paulo: Boitempo, 2013.

PIERRI, Naina. "Historia del desarrollo sustentable". In: Sustentabilidad? Desacuerdos sobre el desarrollo sustentable. FOLADORI, Guillermo. PIERRI, Naina (coord.). México, DF: UAZ, 2005. 
PINTO COELHO, L. X.; MARQUES, L. M. S. "Raça, espaço e direito: reflexões para uma agenda decolonial no Direito Urbanístico". In: José Geraldo de Sousa Junior (Org.). Introdução crítica ao direito urbanístico. 9ed.Brasília: Editora Universidade de Brasília, 2019 , v. 1, p. 137-144.

PORTO-GONÇALVES, Carlos Walter. A reinvenção dos territórios: a experiência latinoamericana e caribenha. In: Los desafios de las emancipaciones en un contexto militarizado. Buenos Aires: CLACSO, 2006.

QUIJANO, Anibal. Cuestiones y horizontes: de la dependencia histórico-estructural a la colonialidad/descolonialidad del poder. Buenos Aires: CLACSO, 2014.

_. "Coloniality of Power and Eurocentrism in Latin America." InternationalSociology 15 (2): 215-32, 2000.

ROLNIK, Raquel. Guerra dos lugares: a colonização da terra e da moradia na era das finanças. São Paulo: Boitempo, 2015.

SANTIAGO, Julliana Ramos;CARVALHO, Ihering Guedes Alcofarado de. 2008. "Teoria Do Desenvolvimento Geográfico Desigual: Uma Reflexão Sobre as Condicionalidades de David Harvey." XIII Encontro Regional de Economia - Fórum BNB de Desenvolvimento, Fortaleza.

SANTOS, Boaventura de Sousa. "Don't shoot the utopist". In: Toward a New Common Sense: Law, science and politics in the paradigmatic transition. Santos, B. S. (org.). New York: Routledge, 1995.

SANTOS, Edmar Ferreira. "Os Batuques Da Cidade: Celebrações Negras e Idéias de Civilização". In: O Poder Dos Candomblés: Perseguição e Resistência no Recôncavo da Bahia, 37-67. Salvador: EDUFBA, 2009.

SIMAS, Luiz Antonio; RUFINO, Luiz. Flecha No Tempo. Rio de Janeiro: Mórula, 2019.

SVAMPA, Maristela. "Modelo de desarrollo e cuestión ambiental em América Latina: categorias y escenarios em disputa". In: WANDERLEY, F. (coord.). El desarrollo em cuestión: reflexiones em América latina. La Paz: CIDES, OXFAN y Plural, 2011.

. "Extrativismo neodesenvolvimentista e movimentos sociais: um giro ecoterritorial rumo a novas alternativas?" In: Descolonizar o imaginário: debates sobre o pós-extrativismo e alternativas ao desenvolvimento. DILGER, Gerhard; LANG, Miriam; PEREIRA FILHO, Jorge (Orgs). São Paulo: Fundação Rosa Luxemburgo, 2016.

SOJA, Edward W. Geografias pós-modernas: a reafirmação do espaço na teoria social crítica. Rio de Janeiro: Zahar, 1993. 
VAINER, Carlos. "Pátria, empresa e mercadoria". In: A cidade do pensamento único: desmanchando consensos. ARANTES, Otília. VAINER, Carlos. MARICATO, Ermínia (Orgs). Petrópolis: Vozes, 2013.

VARGAS, João Costa. "Por Uma Mudança de Paradigma: Antinegritude e Antagonismo Estrutural". Revista de Ciências Sociais 48 (2): 83-105, 2017.

WALLERSTEIN, Immanuel. O universalismo europeu: a retórica do poder. São Paulo: Boitempo, 2007.

WALSH, Catherine. "Interculturalidad y colonialidaddel poder. Um pensamiento y posicionamiento outro desde la diferencia colonial". In: MIGNOLO, Valter; WALSH, Catherine;LINERA, Álvaro García. Interculturalidad, descolonización del estado y del conocimiento. Buenos Aires: Del signo, 2014.

. "Interculturalidad y (de)Colonialidad? Gritos, Grietas e Siembras Desde AbyaYala." Redivep. 2016.

WYNTER, Sylvia. Unsettling the Coloniality of Being/ Power/ Truth/ Freedom. CR: The New CentennialReview, 257-336.

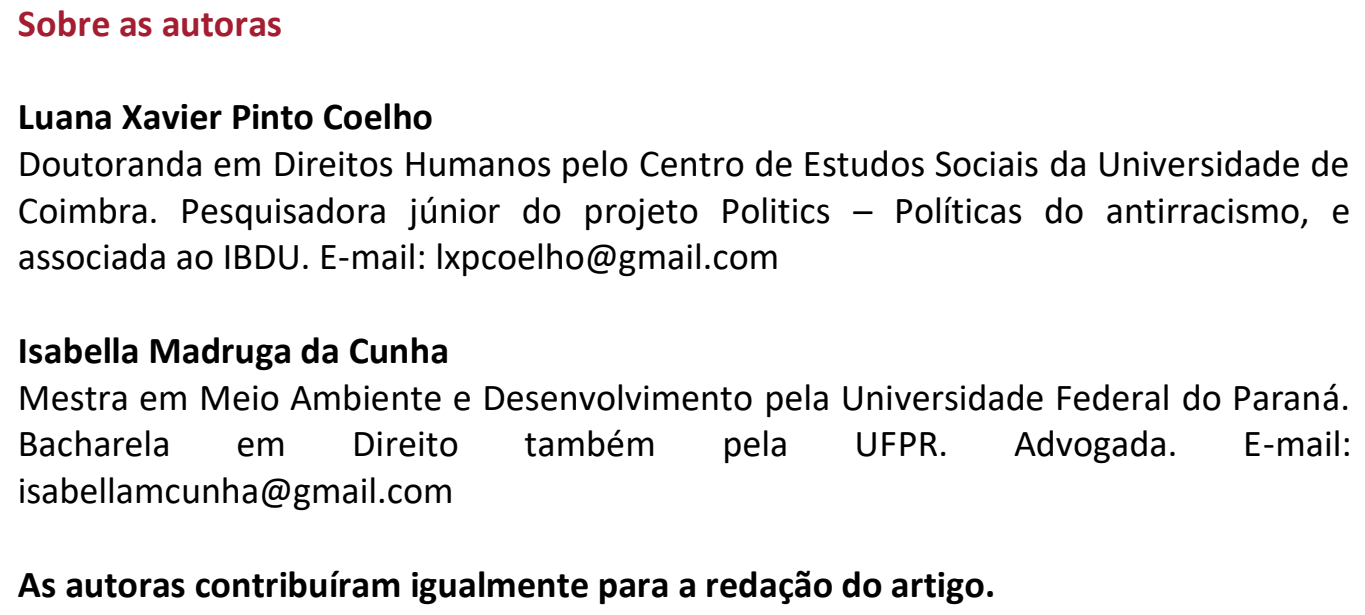

